\title{
Gelation or molecular recognition; is the bis-( $\alpha, \beta$-dihydroxy ester)s motif an omnigelator?
}

\author{
Peter C. Griffiths ${ }^{* 1} \S$, David W. Knight ${ }^{1}$, Ian R. Morgan ${ }^{1}$, Amy Ford ${ }^{1}$, \\ James Brown ${ }^{1}$, Ben Davies ${ }^{1}$, Richard K. Heenan ${ }^{2}$, Stephen M. King ${ }^{2}$, \\ Robert M. Dalgliesh ${ }^{2}$, John Tomkinson ${ }^{2}$, Stuart Prescott ${ }^{3}$, \\ Ralf Schweins ${ }^{4}$ and Alison Paul ${ }^{1}$
}

\section{Full Research Paper}

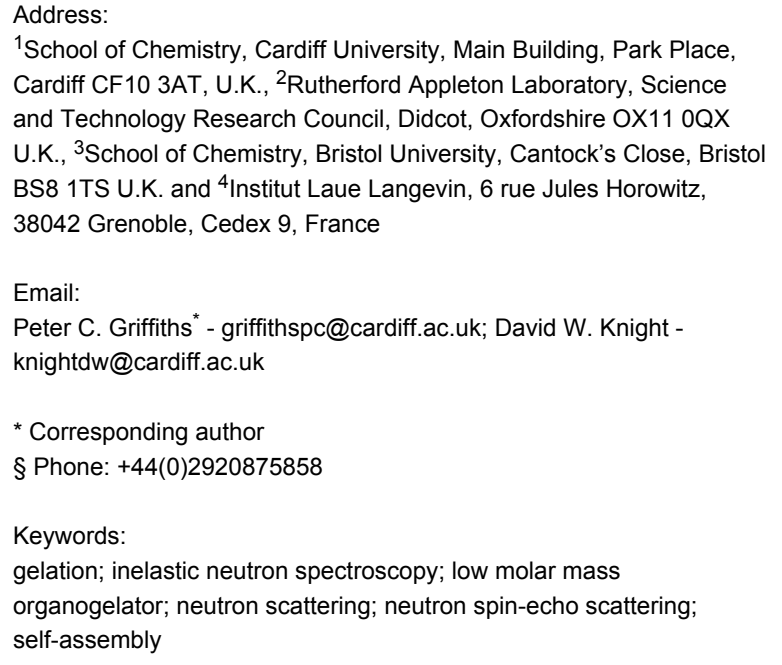

${ }^{1}$ School of Chemistry, Cardiff University, Main Building, Park Place, Cardiff CF10 3AT, U.K., ${ }^{2}$ Rutherford Appleton Laboratory, Science and Technology Research Council, Didcot, Oxfordshire OX11 OQX U.K., ${ }^{3}$ School of Chemistry, Bristol University, Cantock's Close, Bristol BS8 1TS U.K. and ${ }^{4}$ Institut Laue Langevin, 6 rue Jules Horowitz, 38042 Grenoble, Cedex 9, France

Email:

Peter C. Griffiths ${ }^{*}$ - griffithspc@cardiff.ac.uk; David W. Knight knightdw@cardiff.ac.uk

* Corresponding author

§ Phone: $+44(0) 2920875858$

Keywords:

gelation; inelastic neutron spectroscopy; low molar mass

organogelator; neutron scattering; neutron spin-echo scattering;

self-assembly \author{
doi:10.3762/bjoc.6.123 \\ Received: 18 July 2010 \\ Accepted: 02 November 2010 \\ Published: 18 November 2010 \\ Guest Editor: J.-P. Desvergne
}

Beilstein J. Org. Chem. 2010, 6, 1079-1088.

() 2010 Griffiths et al; licensee Beilstein-Institut. License and terms: see end of document.

\footnotetext{
Abstract

Understanding the gelation of liquids by low molecular weight solutes at low concentrations gives an insight into many molecular recognition phenomena and also offers a simple route to modifying the physical properties of the liquid. Bis-( $\alpha, \beta$-dihydroxy ester)s are shown here to gel thermoreversibly a wide range of solvents, raising interesting questions as to the mechanism of gelation. At gelator concentrations of 5-50 mg ml${ }^{-1}$, gels were successfully formed in acetone, ethanol/water mixtures, toluene, cyclohexane and chloroform (the latter, albeit at a higher gelator concentration). A range of neutron techniques - in particular small-angle neutron scattering (SANS) - have been employed to probe the structure of a selection of these gels. The universality of gelation in a range of solvent types suggests the gelation mechanism is a feature of the bis-( $\alpha, \beta$-dihydroxy ester) motif, with SANS demonstrating the presence of regular structures in the 30-40 $\AA$ range. A correlation between the apparent rodlike character of the structures formed and the polarity of the solvent is evident. Preliminary spin-echo neutron scattering studies (SESANS) indicated the absence of any larger scale structures. Inelastic neutron spectroscopy (INS) studies demonstrated that the solvent is largely unaffected by gelation, but does reveal insights into the thermal history of the samples. Further neutron studies of this kind (particularly SESANS and INS) are warranted, and it is hoped that this work will stimulate others to pursue this line of research.
} 


\section{Introduction}

A detailed, molecular level understanding of the fundamental aspects of the spontaneous self-assembly and network formation of low molecular mass organogelators (LMOGS) is still elusive, although much research attempting to quantify the fundamental aspects of this fascinating phenomenon is underway [1-5]. A wide range of structurally diverse gelators have been identified, and in general, whilst a particular gelator functions for a small set of solvents, its gelling ability is not universal [3-11]. This lack of generality doubtless arises as there is generally no single unifying mechanism for gelation, which invariably involves a range of physical (non-covalent) interactions, such as hydrogen bonding, solvophobic effects and $\pi-\pi$ interactions [11-34].

Our previous work has focused on the thermoreversible gelation of partially fluorinated liquids by a homologous series of chiral, non-racemic bis-( $\alpha, \beta$-dihydroxy ester)s [35], in which the gelation character was found to depend on both solvent composition and the molecular structure of the gelator. The enthalpy of melting $\Delta H_{\mathrm{m}}$ for a series of gelators was found to be positive, indicating an endothermic melting process, associated with the increase in entropy. Interestingly, the enthalpies were insensitive to both the solvent composition and the gelator chain length $\left(\mathrm{G}_{n}\right.$, where $n$ corresponds to the number of $\mathrm{CH}_{2}$-groups in the interheadgroup spacer less 2), suggesting that gelation is a feature dominated by the common end-group structural motif. A gelation mechanism based on hydrogen bonding of the endgroup was confirmed by IR and circular dichroism (CD) spectroscopic characterisation. The specific stereochemistry of the gelator end-groups is a crucial factor, providing an obvious analogy to molecular recognition phenomena.

Small-angle neutron scattering provided a detailed insight into the gelator self-assembled structures, with data being best interpreted with a Kholodenko-Dirac worm model, comprising a flexible assembly of rodlike structures, in which the balance between flexibility and rigidity is defined by the parameter $m$. For the fluorinated systems, $m=4$, indicating a rather rigid structure, with a Gaussian cross-section of 25-40 ̊ depending on gelator concentration and structure. The rodlike segments were typically hundreds of $\AA$ in length, suggesting a stacked geometry that was later confirmed with CD spectroscopy. With an increase in temperature, these structures simply "melt", i.e., the size of the structure is largely invariant until the gel temperature is reached. Interestingly, whereas the size and shape of the scatterers was not found to vary significantly with gelator concentration, the scattering intensity did increase with gelator concentration indicating that the number of scatterers increases, leading to the stiffer gels implied by the concomitant increase in $T_{\text {gel-sol }}$ observed.
These gelators form gels in a wide range of solvents, a rather serendipitous and unusual discovery. It is that observation that is elaborated here, and in particular, our focus is to probe the structures present in these gels. To this end, small-angle neutron scattering (SANS) has been used, supplemented in a small number of cases, with inelastic neutron spectroscopy (INS), spin-echo neutron scattering (SESANS), and pulsed-gradient spin-echo (PGSE-)NMR measurements.

\section{Results and Discussion}

A series of bis-( $\alpha, \beta$-dihydroxy ester)s have been found to gel a wide range of solvents at a solvent-specific concentration $\left(\mathrm{C}_{\text {gelator }}\right)$, typically a few $\mathrm{mg}$ per $\mathrm{ml}$, e.g., for $\mathrm{G}_{6} 3.8 \mathrm{mg} \mathrm{ml}^{-1}$ in toluene, $7.1 \mathrm{mg} \mathrm{ml}^{-1}$ in dichloromethane, $4.8 \mathrm{mg} \mathrm{ml}^{-1}$ cyclohexane, $4.1 \mathrm{mg} \mathrm{ml}^{-1}$ in chloroform/hexane (90\% hexane) and $1.8 \mathrm{mg} \mathrm{ml}^{-1}$ in water-rich (75\%) ethanol/water mixtures. The gels formed from water-rich systems and cyclohexane showed varying degrees of opacity, depending on the gelator concentration, but all other systems were transparent. Of the common solvents tested, the only non-gelling system was with acetonitrile. As is evident from this list, these liquids encompass highly polar liquids, nonpolar liquids, and those that are strongly hydrophobic, and at such low gelator concentrations $\left(<10 \mathrm{mg} \mathrm{ml}^{-1}\right)$. It is surprising, therefore, that a single gelator can gel such a wide range of liquids. With the exception of the water/ethanol system, there is a clear correlation of the order of the minimum gelator concentration required (water/ethanol < cyclohexane $\approx$ toluene $<$ dichloromethane $\leq$ acetonitrile) with the dielectric constants (hexane $\approx$ cyclohexane $\approx$ toluene $<$ dichloromethane $<$ ethanol $<$ acetonitrile $\leq$ water), suggesting that the gelation mechanism is driven by the polarity (and therefore, the strength of the hydrogen bonding) sensed by the gelator headgroups.

Figure 1 presents a thermodynamic analysis of gelation for a selection of the gels examined here, focusing specifically on the toluene and ethanol/water gels for gelators $\mathrm{G}_{6}$ and $\mathrm{G}_{8}$ (see Scheme 1 in the Experimental section). In all cases, the gelation temperature increases with concentration, with the toluene gels melting at higher temperatures for the same concentration of gelator, a trend that is more pronounced for the $\mathrm{G}_{6}$ gelator. The higher melting temperature of the toluene gels, typically $20^{\circ} \mathrm{C}$, indicates that the gel is considerably more stable. The slopes of the data in this Schröder-van Laar representation correspond to the enthalpy of melting, and these were found to be $70( \pm 5) \mathrm{kJ} \mathrm{mol}^{-1}$ and $55( \pm 5) \mathrm{kJ} \mathrm{mol}^{-1}$ for the toluene and ethanol/water cases, respectively, and consistent with multiple hydrogen bonds between the headgroups, as found previously in the case of the fluorinated solvents [35]. For the cyclohexane systems, only a fragile gel is observed (even after several 


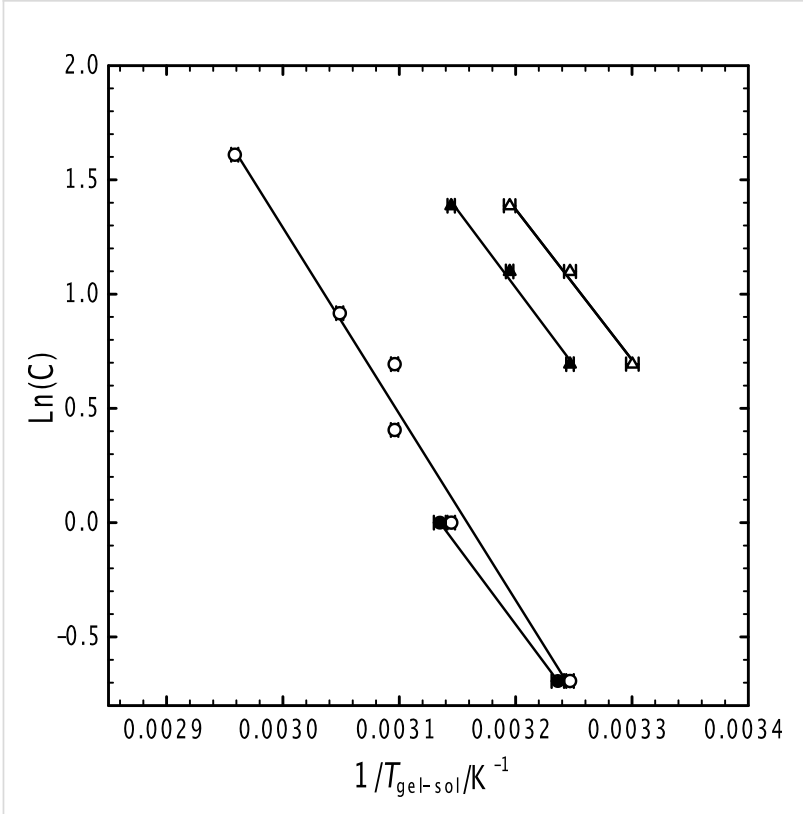

Figure 1: Schröder-van Laar analysis for the melting of toluene (open symbols) and ethanol/water (filled symbols) gels formed from $\mathrm{G}_{6}$ (circles) and $\mathrm{G}_{8}$ gelators (triangles).

heat-cool cycles), over wide ranges of gelator concentration $\left(5<\mathrm{C}_{\text {gelator }}<50 \mathrm{mg} \mathrm{ml}^{-1}\right)$ and temperature $\left(25<T<55^{\circ} \mathrm{C}\right)$, this representing the poorest performance of the gelator.

Representative SANS data are presented in Figures 2-6 from which the morphology of the structures can be extracted in terms of the nature of the solvent (Figure 2), the gelator concentration (Figure 3) and the gelator chain length (Figure 4). These studies have focused on toluene and cyclohexane gels, in which a "contrast variation" approach has been adopted to probe the internal structure of the gels (Figure 5 and Figure 6). The chloroform sample, at this gelator concentration, was not gelled (Figure 2) and no scattering is evident. Thus, we may conclude that there is no aggregation in these solutions that leads to structures large enough to scatter neutrons, i.e., the gelator molecularly dissolves.

The most common macroscopic structural arrangement formed by (chiral) gelators are fibrils formed from a stacking of the gelator molecules [15,16,19,22,27,28,34,36-40], which exhibit "signature" intensity vs. wave-vector $(\mathrm{Q})$ relationships, viz $\mathrm{Q}^{-1}$ (rod) at low $\mathrm{Q}$ becoming $\mathrm{Q}^{-4}$ (Porod scattering from smooth surfaces, characteristic of a well-defined aggregate) at higher $\mathrm{Q}$ in conjunction with local maxima or oscillations usually at higher $\mathrm{Q}$ arising from Bragg reflections or sharp interfaces, or a switch from a $\mathrm{Q}^{-1}$ to a $\mathrm{Q}^{-2}$ dependencies on a double logarithmic I(Q) versus $\mathrm{Q}$ plot [13,41-49]. With the exception of the acetone sample, which shows very weak scattering, all the

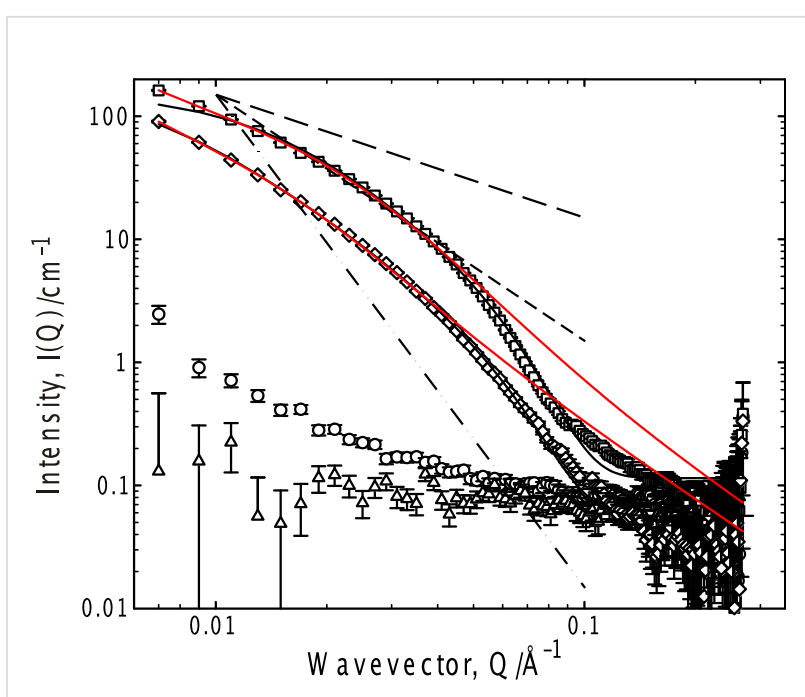

Figure 2: SANS from $50 \mathrm{mg} \mathrm{ml}^{-1} \mathrm{G}_{6}$ in a range of solvents, $25^{\circ} \mathrm{C}$; $d$-acetone (circles), $d$-chloroform (triangles), $50 \% d$-ethanol/ $\mathrm{D}_{2} \mathrm{O}$ (squares) and $d$-toluene (diamonds). Fits to the Kholodenko-Dirac worm model are superimposed on the data as solid black lines, whereas the solid red lines are best attempts to describe the data by a two correlation length model. Limiting behaviors of $Q^{-1}, Q^{-2}$ and $Q^{-4}$ are also shown.

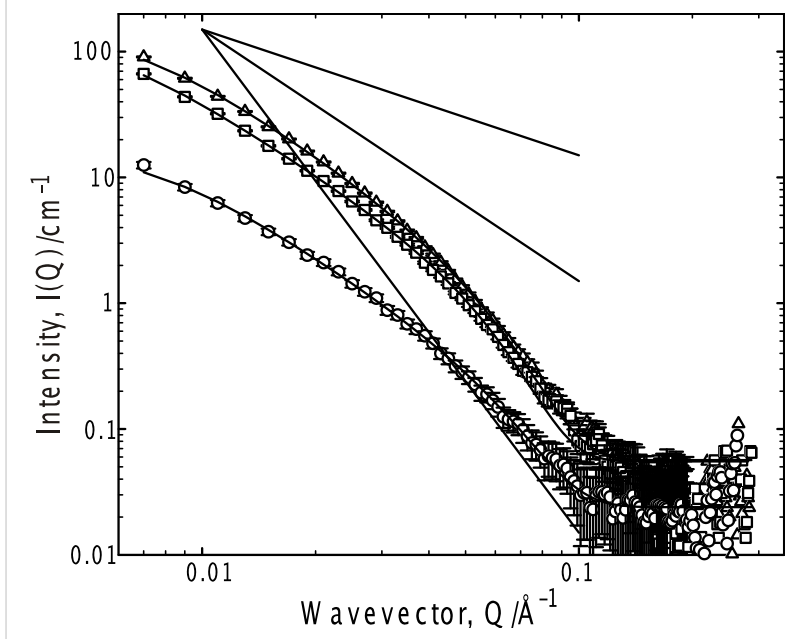

Figure 3: SANS from $\mathrm{G}_{6} 25^{\circ} \mathrm{C}$ in d-toluene as a function of $\mathrm{G}_{6}$ concentration; $5 \mathrm{mg} \mathrm{ml}^{-1}$ (circles), $10 \mathrm{mg} \mathrm{ml}^{-1}$ (squares) and $50 \mathrm{mg}$ $\mathrm{ml}^{-1}$ (triangles). Fits to the Kholodenko-Dirac worm model are superimposed on the data. Limiting behaviors of $Q^{-1}, Q^{-2}$ and $Q^{-4}$ are also shown.

systems show a smooth transition from a simple $\mathrm{Q}^{-1}$ dependence indicative of rodlike structures, into the $\mathrm{Q}^{-4}$ expected for well-defined objects. This latter dependence $\left(\mathrm{Q}^{-4}\right)$ is most evident in $75 \% \mathrm{D}_{2} \mathrm{O} / d$-ethanol, implying the structure in this case is more particle-like, consistent with the fragility (and appearance) of this gel. Clearly, existing frameworks for analyzing such data are not appropriate here. 


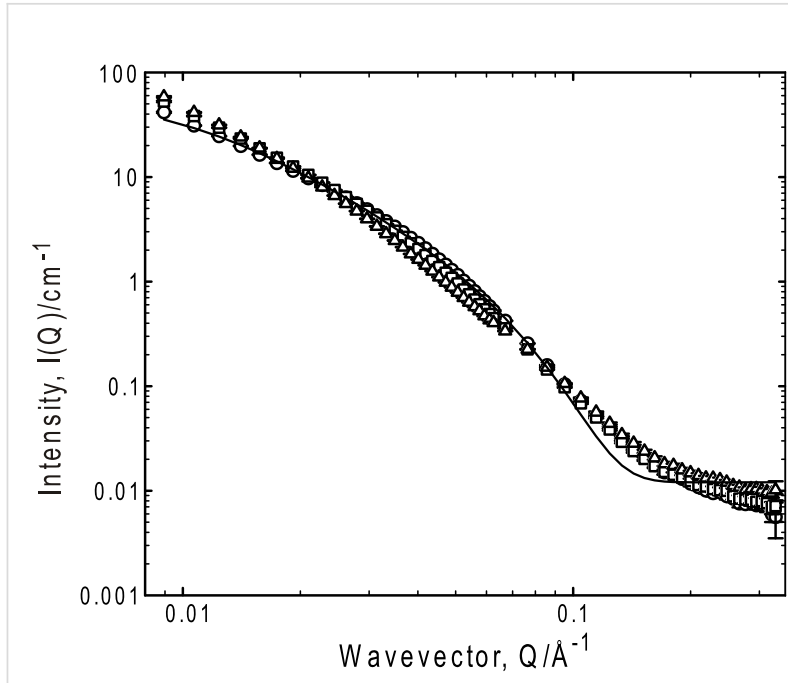

Figure 4: SANS from a series of homologous gelators, $\mathrm{G}_{5}$ (circles), $\mathrm{G}_{6}$ (squares) and $\mathrm{G}_{8}$ (triangles) in $d$-toluene, all at $50 \mathrm{mg} \mathrm{ml}^{-1}$ and $25^{\circ} \mathrm{C}$. Selected fits to the Kholodenko-Dirac worm model are superimposed on the data.

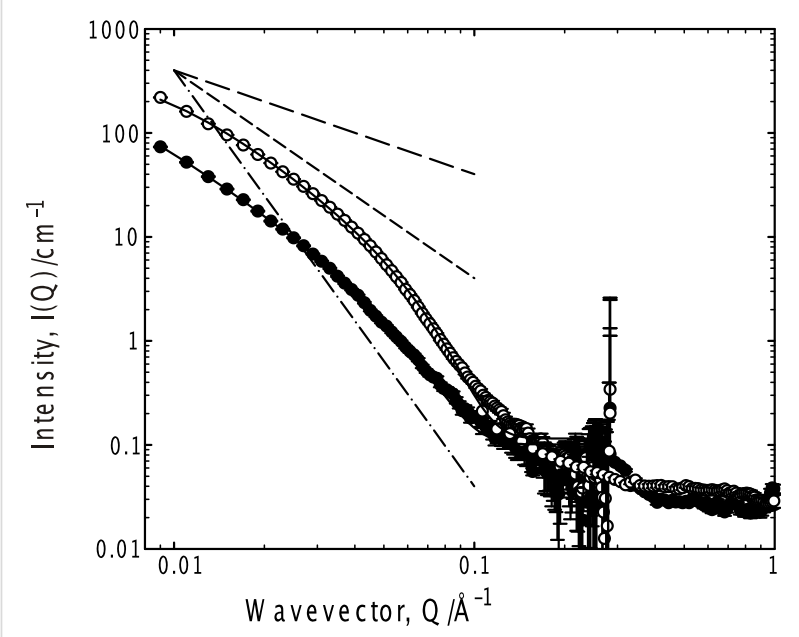

Figure 5: SANS from $50 \mathrm{mg} \mathrm{ml}^{-1} \mathrm{G}_{6}$ in $d$-toluene, $25^{\circ} \mathrm{C}$; hydrogenous gelator (empty symbols) and partially deuterated gelator (filled symbols). Fits to the Kholodenko-Dirac worm model are superimposed on the data. Limiting behaviors of $Q^{-1}, Q^{-2}$ and $Q^{-4}$ are also shown.

In order to identify an appropriate theoretical framework with which to analyze these data, it is important to probe for any interaction between the structures - to ascertain whether the data may be analyzed merely in terms of their morphology or if there is an additional contribution from inter aggregate correlations. This is most easily assessed by recording the scattering from a series of gels as a function of the gelator concentration. The concentration dependence of the scattering from $\mathrm{G}_{6}$ was therefore studied over a wide range of concentration, and representative data is presented for the toluene system in

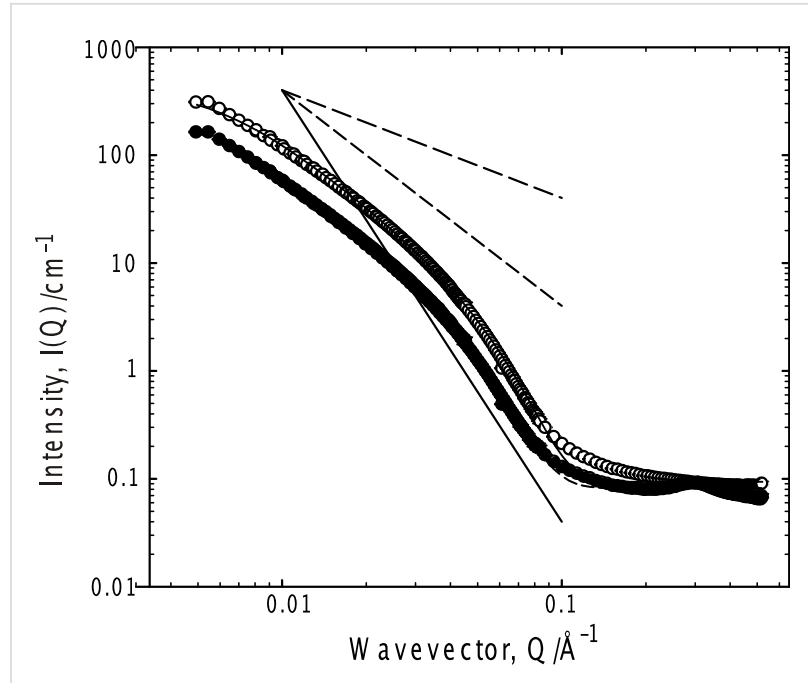

Figure 6: SANS from $35 \mathrm{mg} \mathrm{ml}^{-1} \mathrm{G}_{6}$ in $75 \%$ d-ethanol/25\% $\mathrm{D}_{2} \mathrm{O}, 37$ ${ }^{\circ} \mathrm{C}$; hydrogenous gelator (empty symbols) and partially deuterated gelator (filled symbols). Fits to the Kholodenko-Dirac worm model are superimposed on the data. Limiting behaviors of $Q^{-1}, Q^{-2}$ and $Q^{-4}$ are also shown.

Figure 3. The toluene system was chosen as there is appreciable scattering in this system, even just above the minimum gelation concentration.

From this system presentation, it is obvious that the functional form of the scattering does not follow a simple Q dependence at any concentration of gelator and that this complex functional form is invariant with concentration. This observation therefore, allows the data analysis to ignore incorporation of a term describing an interaction between the aggregates. Further, one may conclude that the changes in scattering arise from an increase in the number of structures, with perhaps subtle changes in their size or morphology (at least over this range), i.e., gelation is akin to the simple self-assembly process demonstrated by surfactants, and is a consequence of a cooperative process. Given the morphology of the scatterers, this is most likely to arise due to growth along the long axis (elongation) of the structures.

An analysis protocol has therefore been adopted that reflects the smooth transition in Q dependence observed in these systems, viz a flexible wormlike structure, parameterized by the Kholodenko-Dirac model. This model is based on a Gaussian coil comprising multiple $(m)$ cylindrical elements of statistical length $(\ell)$ and radius $\left(R_{A x}\right)$. The parameter $m$ can be considered a measure of the balance of the Gaussian to rigid rod character when $m$ is large, and both $\ell$ and $R_{A x}$ small, the limiting behavior of this model is effectively that of a Gaussian Debye coil, whereas when $m$ is small and $\ell$ large, the limiting behavior is that of a rigid rod. 
Representative fit parameters are given in Table 1, and the model predictions overlaid on the experimental scattering in all the figures. The fitting is most sensitive to the radial crosssection of the structure $\left(R_{A x}\right)$, invariably with a radius of 25-35 $\AA$. Converting this Guinier radius to an equivalent cylindrical radius (multiply by $\sqrt{2}$ ), and if one considers a disc of thickness $1 \AA$ and the volume of a gelator molecule to be $600 \AA^{3}$, that disc contains on average $6 \pm 1$ molecules, consistent with the proposed number of hydrogen bonds between the end-groups of the gelator molecules [35]. Further, the universality of the radius would seem to be a feature of the gelator structure rather than the solvent, i.e., self-association driven by a molecular recognition process, as opposed to a classical aggregation such as that observed in surfactants. There is a negligible variation in the scattering behavior with increasing gelator length, as might be expected were a bilayer structure present. In all cases, the fitting procedure was tested to ensure that the best fit observed was a global minimum, especially since there is some coupling of the parameters $m$ and $\ell$.

The internal morphology of the structures may be elaborated by considering a partially deuterated gelator, in which the endgroups no longer contribute to the scattering, an experimental approach known as "contrast variation". For both the toluene and $25 \%$ ethanol/water systems, there is no significant change in the form of the scattering (merely the intensity) when the partially (headgroup) deuterated gelator is used, although the relative change in intensity, typically a factor of $3 \pm 0.5$, is somewhat smaller than would be expected given a homogeneous structure. This indicates that the headgroups and the alkyl sections of the gelator exhibit a very similar morphology, but there is some spatial separation within the structure between the headgroups and the alkyl chain. Further, the deuterated gelator data show a weak peak at $\mathrm{Q} \approx 0.3 \AA^{-1}$, corresponding to a dimension of approx. $20 \AA$. Given that the length of the alkyl spacer is approximately $10 \AA$, the simplest interpretation of this distance is the characteristic length associated with the correlation between the (deuterated) end-groups of two end-on gelator molecules. If this arrangement were heavily populated in the aggregate, one would also expect to see a feature on the SANS around a $\mathrm{Q}$ commensurate with the $10 \AA$ distance, i.e., $\mathrm{Q}=$ $0.6 \AA^{-1}$, but the data are not of sufficient quality to state whether the features at this $Q$ are significant or not. It should be noted that a core-shell morphology was also tested, but the peak could only be reproduced by assuming unphysical parameters a $10 \AA$ in length alkyl spacer and a $20 \AA$ headgroup region whilst the fit at low $\mathrm{Q}$ was poor.

If one considers the trends in the Gaussian coil-rigid rod character $(m)$ and the length $(\ell)$ of the rods comprising the building blocks of the gelled structure, i.e., for $m$; fluorinated solvent $\approx$ acetone $\approx$ ethanol/water $<$ chloroform $<$ toluene, whereas for $\ell$; chloroform $\approx$ fluorinated solvent $\approx$ toluene $<<$ ethanol/water $\approx$ acetone, it is clear that more Gaussian coil- or particlelike structures are evident when the hydrogen bonding is weaker.

The fitted parameters, combined with the absolute intensities, may be used to further elaborate the structure of the gelator assemblies. Taking the parameters listed in Table 1 and the absolute intensity, the number of worms per unit volume, N, may be calculated, along with the number of molecules per worm, and ultimately the number of gelator molecules per worm per unit length. For all the data presented here, this characteristic number is surprisingly invariant across the systems, typically $8 \pm 2$ molecules, not inconsistent with the estimate of the same parameter derived from the radius of the rodlike element $(6 \pm 1)$.

\begin{tabular}{|c|c|c|c|c|}
\hline [Gelator]/wt \% & Solvent & $\begin{array}{l}\text { Number of links } \\
\mathrm{m}\end{array}$ & $\begin{array}{l}\text { Length of link, I } \\
\AA\end{array}$ & $\begin{array}{l}\text { Radial cross-section } \\
R_{A x} / \AA\end{array}$ \\
\hline$\left[G_{6}\right]=0.5$ & toluene & $30( \pm 2)$ & $90( \pm 5)$ & $28( \pm 1)$ \\
\hline$\left[G_{6}\right]=1.0$ & toluene & $30( \pm 3)$ & $110( \pm 8)$ & $30( \pm 1)$ \\
\hline$\left[\mathrm{G}_{6}\right]=5.0$ & toluene & $55( \pm 5)$ & $100( \pm 10)$ & $30( \pm 2)$ \\
\hline$\left[\mathrm{G}_{6}\right]=5.0$ & acetone & \multicolumn{3}{|c|}{ Does not fit to Kholodenko-Dirac worm model, simple rod Q dependence } \\
\hline$\left[\mathrm{G}_{6}\right]=5.0$ & $50 \%$ ethanol/water & $4( \pm 0.2)$ & $200( \pm 20)$ & $33( \pm 2)$ \\
\hline$\left[\mathrm{G}_{6}\right]=10.0$ & chloroform & $13( \pm 2)$ & $100( \pm 10)$ & $25( \pm 1)$ \\
\hline$\left[\mathrm{G}_{6}\right]=10.0$ & acetone & $4( \pm 1)$ & $220( \pm 8)$ & $30( \pm 2)$ \\
\hline$\left[\mathrm{G}_{6}\right]=10.0$ & ethanol & $55( \pm 10)$ & $85( \pm 10)$ & $20( \pm 3)$ \\
\hline$d-\left[\mathrm{G}_{6}\right]=5.0$ & toluene & $55( \pm 10)$ & $100( \pm 10)$ & $30( \pm 3)$ \\
\hline$h-\left[\mathrm{G}_{6}\right]=5.0$ & toluene & $60( \pm 5)$ & $80( \pm 10)$ & $25( \pm 3)$ \\
\hline$d-\left[\mathrm{G}_{6}\right]=5.0$ & $25 \%$ ethanol/water & $480( \pm 3)$ & $32( \pm 2)$ & $27( \pm 2)$ \\
\hline$h-\left[\mathrm{G}_{6}\right]=5.0$ & $25 \%$ ethanol/water & $460( \pm 3)$ & $30( \pm 2)$ & $26( \pm 2)$ \\
\hline
\end{tabular}


A variation of the scattering experiment, SESANS, has been used to probe the existence of any structural order on a length scale greater than a few tens of nanometers up to several microns, Figure 7, for the toluene gels. In this experiment,

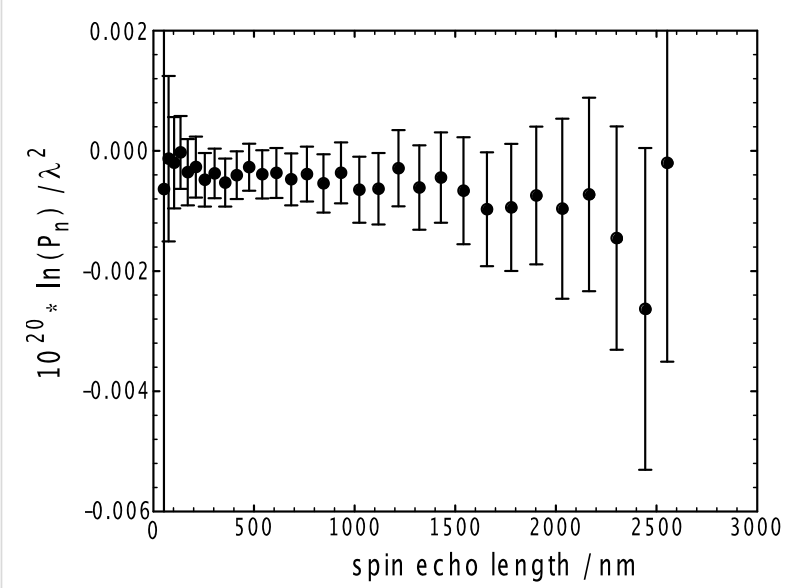

Figure 7: SESANS data for $50 \mathrm{mg} \mathrm{ml}^{-1} \mathrm{G}_{6}$ in deuterated toluene, $25^{\circ} \mathrm{C}$.
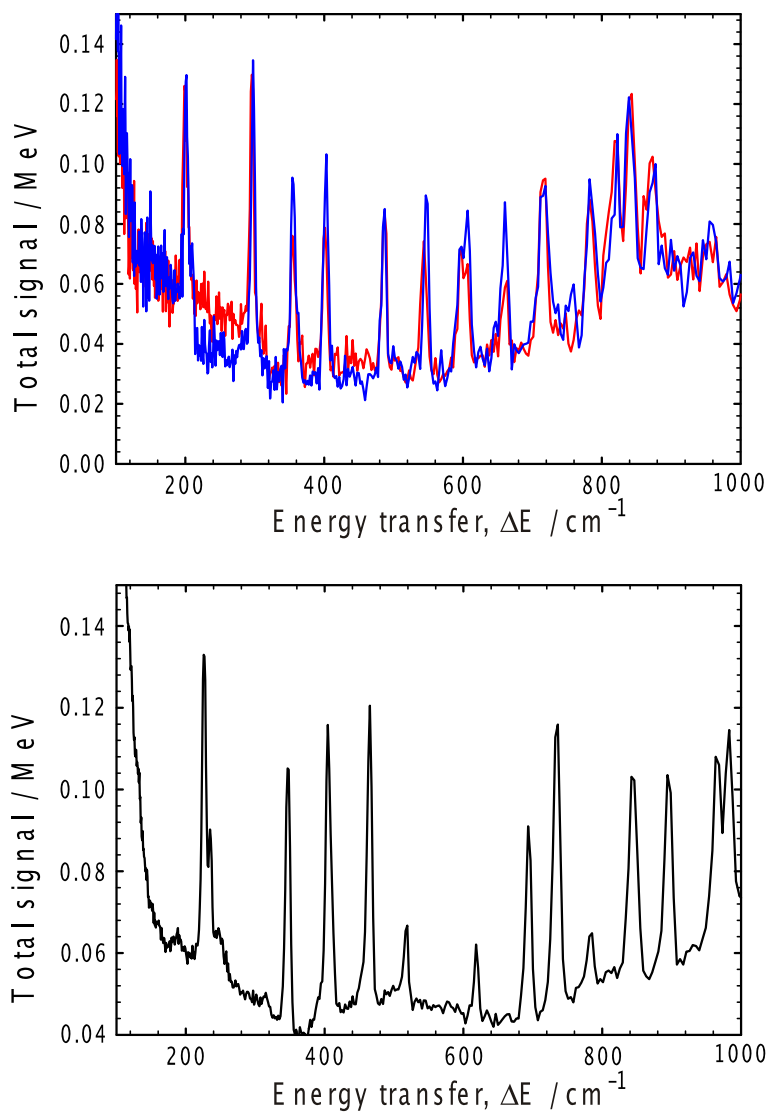

Figure 8: Inelastic neutron spectroscopy from toluene gels (upper Figure): red deuterated toluene/hydrogenous gelator, blue deuterated toluene/deuterated gelator, and the pure solvent (lower trace). polarized neutrons are used as a probe of long-range order. Polarized and nonpolarized neutrons probe structure differently, such that the ratio of their intensities is a measure of any structure present, over a distance scale defined by the evolution period used in the experiment. For the gels studied here, this ratio was constant at a value of unity, indicating a complete lack of higher order structure present in these systems, and one may conclude that there is no long-range ordering or association of the fibrils, i.e., they are randomly dispersed over these characteristic length scales.

The characteristics of the solvent in these gels have been examined by inelastic neutron spectroscopy (INS), Figure 8 and Figure 9, for the toluene and cyclohexane gels, respectively. For the toluene gels, the observed gel spectra are dominated by the toluene spectrum (Figure 8 ). There are very subtle differences between the $h$ - and $d$-gelator spectra, these being most obvious in the $\mathrm{OH}$ stretching region around $3000 \mathrm{~cm}^{-1}$ and in the low frequency region below $150 \mathrm{~cm}^{-1}$. However, the data in these regions are too broad and statistically too poor to extract any detailed interpretation, but it is comforting that the spectra are
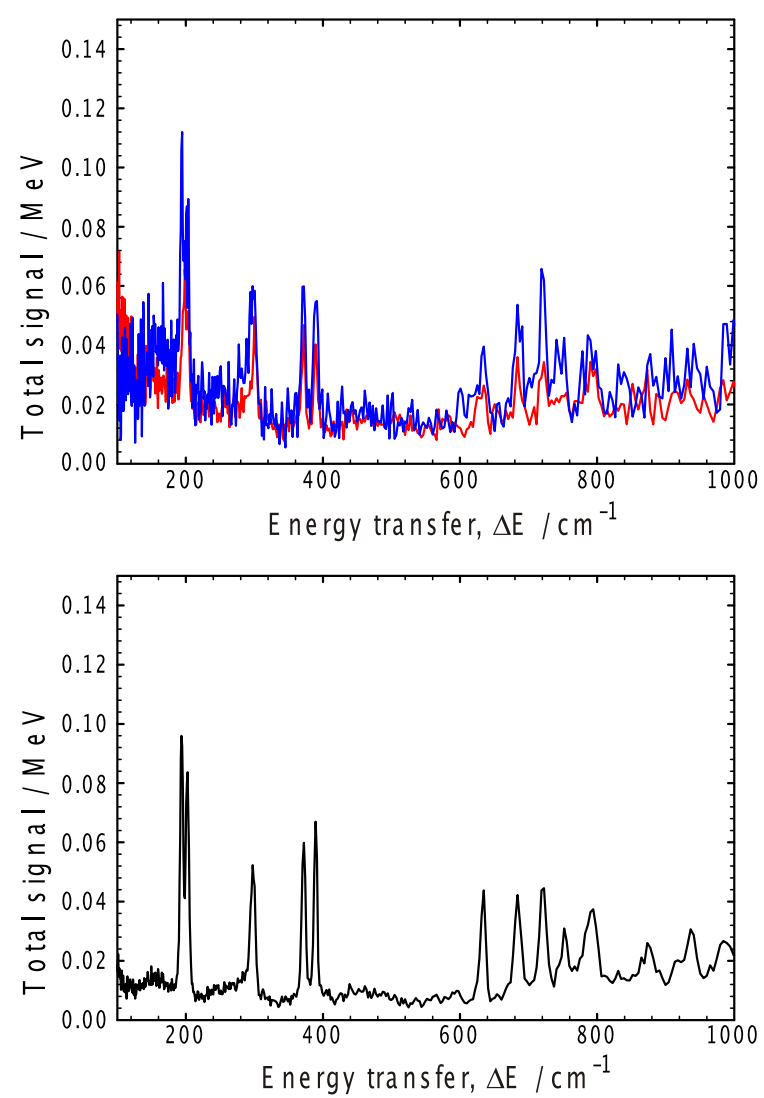

Figure 9: Inelastic neutron spectroscopy from cyclohexane gels (upper Figure): red deuterated cyclohexane/hydrogenous gelator, blue deuterated cyclohexane/deuterated gelator, and the pure solvent (lower Figure). 
different in those regions of the spectrum where the peaks due to those functional groups that have been altered by deuteration would be expected.

The nine sharp features between 150 and $800 \mathrm{~cm}^{-1}$ arising from the $d$-toluene in the gelled samples are of considerably more interest, indicating that the average environment of the toluene methyl groups are significantly different. This difference may have a number of origins, one of which may be as a result of deuteration, but it is much more likely due to unavoidable thermal histories of the two samples (cooling rates, time elapsed since the initial freezing). Further, it is not possible to normalize the spectra such that all of these nine bands overlap completely with the same intensity in both spectra, again a consequence of differences in the samples rather than for example, spectrometer performance or gelation. Thus, it is probable that the differences in the spectra observed for the $d$-toluene gels arise as a result of two populations of coexisting solvent phases - the amorphous phase that has a structural arrangement of the molecules similar to that in the unstable $\beta$-toluene phase [50] and the more stable $\alpha$-toluene phase - since the average barrier to methyl rotation in the amorphous phase is higher than the barrier heights in either the $\alpha$ - or $\beta$-phases [51]. Hence, when comparing two samples such as we do here, if the average barrier to methyl rotation is less in one sample than the second, the methyl group's Debye-Waller factors that control that portion of the intensities in the observed bands arising from the methyl groups will differ, thereby accounting for the observed variations in the intensity of those bands involving most methyl group vibrations. A similar conclusion - that the solvent does not participate in the gelation mechanism - may be drawn from the cyclohexane data; again, the two spectra are very similar, the key differences being in the bands relating to the isopropyl dynamics.

Finally, the self-diffusion coefficients of the solvents (toluene, cyclohexane, water/ethanol) in these gels (at $25^{\circ} \mathrm{C}$ ) have been measured by PGSE-NMR (data not presented), and compared with the self-diffusion coefficients in the appropriate bulk solutions. A very slight retardation in the diffusion of the solvent is observed, consistent with the obstruction effect introduced by the assemblies of the gelator molecules, as the solvent molecules must diffuse around the structures, thereby increasing their diffusion path length.

\section{Conclusion}

A diverse range of liquids has been successfully gelled with low concentrations of a low molecular weight gelator incorporating $b i s-(\alpha, \beta$-dihydroxy ester) end-group motifs. Gelation is caused by association of gelator molecules into stacks, due to intermolecular hydrogen bonding between the end-groups. The crit- ical dimensions of these structures have been determined by analysis of neutron scattering data (SANS and SESANS), and are dependent on the strength of the intermolecular hydrogen bonding interaction. The strongest gels are formed in solvents where stronger intermolecular hydrogen bonds lead to longer segments and less flexible structures, whereas shorter, more flexible segments lead to a particlelike gelator structure which can only form weak gels. PGSE-NMR confirms retardation of solvent diffusion due to an obstruction effect. Preliminary INS data exhibit subtle differences providing an insight into the thermal history of the sample, but not the gelation mechanism.

\section{Experimental Materials}

All solvents were of spectroscopic grade and used as received.

\section{Synthesis of gelators}

The omnigelator 4 was prepared as previously described [52] by sequential Grubbs double cross metathesis [53] between $(Z)$ cyclodecene (1) and two equivalents of isopropyl acrylate $\mathbf{2}$, which routinely delivered $80-85 \%$ yields of the bisenoate $\mathbf{3}$, exclusively as the (E,E)-isomer shown (Scheme 1), followed by an AD-mix double bishydroxylation with (DHQD) ${ }_{2} \mathrm{PHAL}$ as the chiral ligand [54].

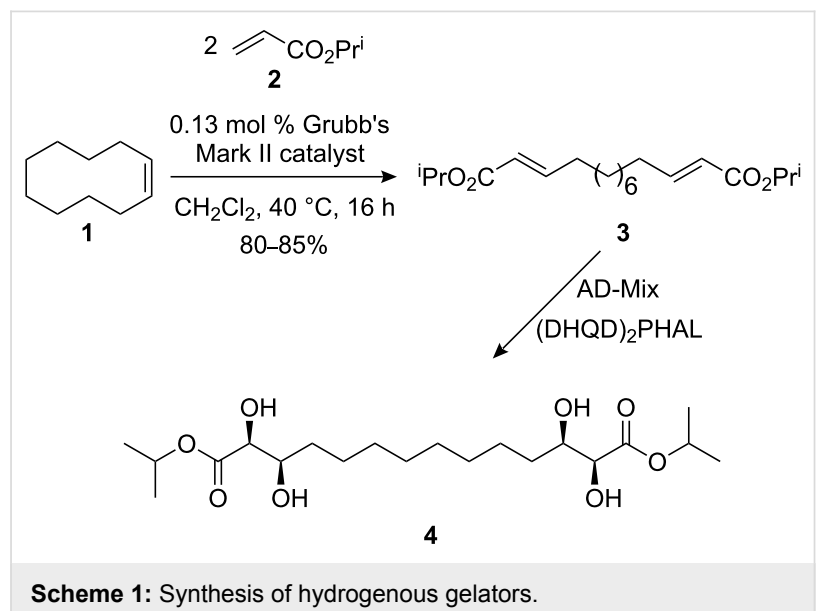

The deuterated analogue 6, Scheme 2, was prepared by using $d_{7}$-isopropyl acrylate (5) in the initial cross metathesis step. The deuterated ester 5 was prepared from acryloyl chloride and $d_{7}$-isopropanol $\left(\mathrm{Et}_{3} \mathrm{~N}, \mathrm{CH}_{2} \mathrm{Cl}_{2}, 0 \rightarrow 20{ }^{\circ} \mathrm{C}, 2 \mathrm{~h}\right.$ ); yields were essentially identical to the nondeuterated example, given that the deuterated acrylate $\mathbf{5}$ was carefully purified and was completely free of triethylamine, which is a very effective ligand and quench for the Grubbs Mark II metathesis catalyst. This was achieved by extensive washing during work-up (water, sat. aq $\mathrm{NH}_{4} \mathrm{Cl}, 1 \mathrm{M} \mathrm{HCl}$, sat. aq $\mathrm{K}_{2} \mathrm{CO}_{3}$, water and brine) followed by distillation, bp $\sim 40{ }^{\circ} \mathrm{C}$ at $17 \mathrm{~mm} \mathrm{Hg}$. 


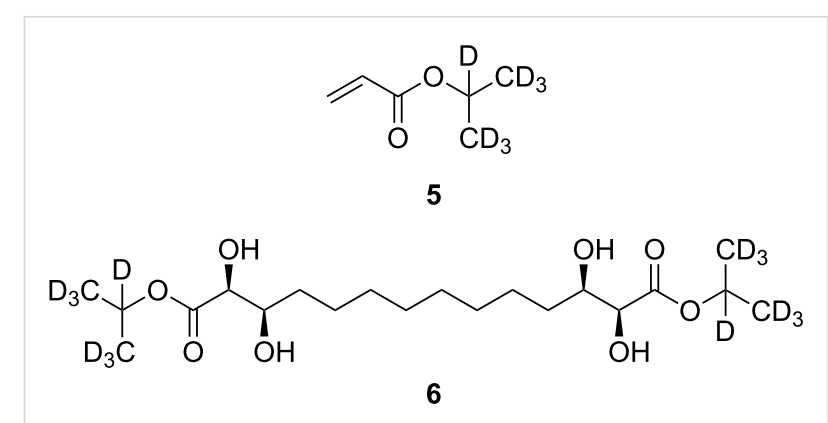

Scheme 2: Structure of partially deuterated gelators.

\section{Gel formation}

On a $0.5 \mathrm{~g}$ scale, the gelator and solvent were weighed directly into a screw top vial. A simple heat-cool cycle was necessary for several of these gels to ensure homogeneity, although several heterogeneous gels did form spontaneously at room temperature.

\section{Determination of gelation temperature $T_{\text {gel-sol }}$}

Glass vials containing the samples were equilibrated in a temperature-controlled water bath and the temperature increased from $15{ }^{\circ} \mathrm{C}$ initially in $2{ }^{\circ} \mathrm{C}$ steps with a 30 min equilibration time at each temperature. On approaching the gelation temperature, smaller increments $\left(0.5^{\circ} \mathrm{C}\right)$ were adopted. The simplest measure of gelation - that the gel be stable to inversion [3] - was used to quantify the gel-sol behavior.

\section{Small-Angle Neutron Scattering (SANS)}

Small-angle neutron scattering (SANS) measurements were performed on either (a) the fixed-geometry, time-of-flight LOQ diffractometer (ISIS Spallation Neutron Source, Oxfordshire, UK) or (b) on the D11 diffractometer at the ILL, Grenoble. On LOQ, a white beam of radiation with neutron wavelengths spanning 2.2 to $10 \AA$ were used to access a $Q[Q=4 \pi \sin (\theta / 2) / \lambda]$ range of 0.008 to $0.25 \AA^{-1}(25 \mathrm{~Hz})$, with a fixed sampledetector distance of $4.1 \mathrm{~m}$. On D11, a neutron wavelength of $6 \AA$ was employed to access a Q-range of approximately 0.005 to $0.50 \AA^{-1}$, requiring three separate instrument configurations (sample-detector distances and collimation).

On both instruments, the samples were contained in $2 \mathrm{~mm}$ path length, UV-spectrophotometer grade, quartz cuvettes (Hellma) and mounted in aluminium holders on top of an enclosed, computer-controlled, sample chamber. Sample volumes were approximately $0.4 \mathrm{~cm}^{3}$. Temperature control was achieved through the use of a thermostatted circulating bath pumping fluid through the base of the sample chamber. Under these conditions a temperature stability of better than $\pm 0.5^{\circ} \mathrm{C}$ can be achieved. Experimental measuring times were approximately $40 \mathrm{~min}$.
All scattering data were (a) normalized for the sample transmission, (b) background corrected using an empty quartz cell or one filled with the appropriate solvent (this also removes the inherent instrumental background arising from vacuum windows, etc) and (c) corrected for the linearity and efficiency of the detector response using the instrument-specific software package. The data were put onto an absolute scale by reference to the scattering from a partially deuterated polystyrene blend (LOQ) or $1 \mathrm{~mm} \mathrm{H}_{2} \mathrm{O}$.

The Kholodenko-Dirac wormlike chain model [9] has been used to analyse the SANS data. This approach is derived from a Gaussian coil model, where long thin rods are made of a succession of $m$ cylindrical elements of statistical length $\ell$ and radius $R_{A x}$. The contour length of the chain, $\mathrm{L}$, is equal to the product $m \cdot \ell$. The scattering intensity generated from Kholodenko-Dirac wormlike chains is proportional to two terms:

$$
I(Q)=P_{W o r m}(Q) * P_{\text {Axial }}(Q)+B_{\text {inc }}
$$

where $B_{i n c}$ is the incoherent background. The Kholodenko-Dirac model therefore smoothly interpolates between the Gaussian coil and rigid rod predictions and the number of segments $(m)$ forming the chain, and hence gives an indication regarding the flexibility of the chain. Smaller values of $m$ correspond to stiffer chains. When $m$ tends towards infinity, the scatterer adopts a flexible Gaussian random coil whereas when tending towards unity, a rigid rod is obtained.

For long thin rods

$$
P_{W o r m}(Q)=\frac{2}{3 n} \int_{0}^{3 n}\left(1-\frac{y}{3 n}\right) f(y) d y
$$

where for

$$
\begin{gathered}
Q \leq \frac{3}{l}, \\
f(y)=\frac{\sinh (E y)}{E \sinh (y)}
\end{gathered}
$$

with

$$
E=\left[1-\left(\frac{Q l}{3}\right)^{2}\right]^{1 / 2}
$$


whereas for

$$
\begin{gathered}
Q>\frac{3}{l}, \\
f(y)=\frac{\sin (F y)}{F \sinh (y)}
\end{gathered}
$$

with

$$
F=\left[\left(\frac{Q l}{3}\right)^{2}-1\right]^{1 / 2}
$$

given that $m$ is the number of chain elements, $l$ the statistical chain element length (giving the total chain length $\mathrm{L}=m \cdot l$ ).

$P_{\text {Axial }}(\mathrm{Q})$ was adopted with a radial Guinier form, such as:

$$
P_{\text {Axial }}(Q)=N\left(\rho_{1}-\rho_{3}\right)^{2}(A L)^{2} \exp \left(-\frac{1}{2} Q^{2} R_{A x}^{2}\right)
$$

with $\rho_{1}$ and $\rho_{3}$ the scattering length densities for the worm and solvent, $N$ worms per unit volume, $A$ the cross sectional area and $R_{A x}$ the cross sectional radius of the chain, assuming a Gaussian scattering density.

\section{Inelastic Neutron Scattering (INS)}

The samples, about $0.5 \mathrm{~g}$ each, were held in air-tight sample holders and rapidly cooled to $20 \mathrm{~K}$ in the TOSCA neutron spectrometer, ISIS Facility, the Rutherford Appleton Laboratory, Harwell Science and Innovation Campus, OX11 0QX, UK. TOSCA is a pulsed neutron, indirect geometry, low bandpass spectrometer with good spectral resolution $\left(\Delta E_{\mathrm{t}} / E_{\mathrm{t}} \approx\right.$ 1-2\%), further details are given elsewhere [55]. Data were collected for about $8 \mathrm{~h}$ and transformed into the conventional scattering law, $\mathrm{S}(Q, \omega)$ (arbitrary units), vs. energy transfer, $E_{\mathrm{t}}\left(\mathrm{cm}^{-1}\right)$, using standard programs.

\section{Acknowledgements}

EPSRC (EP/C013220/1), Cardiff and Bristol Universities are acknowledged for financial support. STFC is gratefully acknowledged for consumables support and access to neutron facilities.

\section{References}

1. Gronwald, O.; Snip, E.; Shinkai, S. Curr. Opin. Colloid Interface Sci. 2002, 7, 148-156. doi:10.1016/S1359-0294(02)00016-X

2. Abdallah, D. J.; Weiss, R. G. J. Braz. Chem. Soc. 2000, 11, 209-218.
3. Terech, P.; Weiss, R. G. Chem. Rev. 1997, 97, 3133-3159. doi:10.1021/cr9700282

4. Sangeetha, N. M.; Maitra, U. Chem. Soc. Rev. 2005, 34, 821-836. doi:10.1039/b417081b

5. Smith, D. K., Ed. Tetrahedron Symposia-in-Print on Low molecular Weight Organic Gelators, July 30, 2007; Elsevier, 2007.

6. Escuder, B.; Miravet, J. F. Langmuir 2006, 22, 7793-7797. doi:10.1021/la060499w

7. Luboradzki, R.; Gronwald, O.; Ikeda, M.; Shinkai, S.; Reinhoudt, D. N. Tetrahedron 2000, 56, 9595-9599. doi:10.1016/S0040-4020(00)00915-7

8. Mieden-Gundert, G.; Klein, L.; Fischer, M.; Vogtle, F.; Heuze, K.; Pozzo, J. L.; Vallier, M.; Fages, F. Angew. Chem., Int. Ed. 2001, 40, 3164-3166. doi:10.1002/1521-3773(20010903)40:17<3164::AID-ANIE3164>3.0.CO ;2-B

9. Weiss, R. G.; Terech, P. Molecular Gels - Materials with Self-Assembled Fibrillar Networks; Springer: Dordrecht, The Netherlands, 2006.

10. Yoza, K.; Ono, Y.; Yoshihara, K.; Akao, T.; Shinmori, H.; Takeuchi, M.; Shinkai, S.; Reinhoudt, D. N. Chem. Commun. 1998, 907-908. doi:10.1039/a800825f

11. Yoza, K.; Amanokura, N.; Ono, Y.; Akao, T.; Shinmori, H.; Takeuchi, M.; Shinkai, S.; Reinhoudt, D. N. Chem.-Eur. J. 1999, 5, 2722-2729. doi:10.1002/(SICI)1521-3765(19990903)5:9<2722::AID-CHEM2722>3. $0 . \mathrm{CO} ; 2-\mathrm{N}$

12. Burkhardt, M.; Kinzel, S.; Gradzielski, M. J. Colloid Interface Sci. 2008, 331, 514-521. doi:10.1016/j.jcis.2008.11.078

13. George, M.; Snyder, S. L.; Terech, P.; Glinka, C. J.; Weiss, R. G. J. Am. Chem. Soc. 2003, 125, 10275-10283. doi:10.1021/ja0362407

14. George, M.; Snyder, S. L.; Terech, P.; Weiss, R. G. Langmuir 2005, 21, 9970-9977. doi:10.1021/la050371z

15. Bao, C. Y.; Jin, M.; Lu, R.; Song, Z. G.; Yang, X. C.; Song, D. P.; Xu, T. H.; Liu, G. F.; Zhao, Y. Y. Tetrahedron 2007, 63, 7443-7448. doi:10.1016/j.tet.2007.03.125

16. Bag, B. G.; Maity, G. C.; Pramanik, S. R. Supramol. Chem. 2005, 17, 383-385. doi:10.1080/10610270500114640

17. Brizard, A.; Oda, R.; Huc, I. Top. Curr. Chem. 2005, 256, 167-218.

18. Snijder, C. S.; deJong, J. C.; Meetsma, A.; van Bolhuis, F.; Feringa, B. L. Chem.-Eur. J. 1995, 1, 594-597. doi:10.1002/chem.19950010905

19. Haino, T.; Tanaka, M.; Fukazawa, Y. Chem. Commun. 2008, 468-470. doi:10.1039/B715871H

20. Babu, P.; Sangeetha, N. M.; Maitra, U. Macromol. Symp. 2006, 241 , 60-67. doi:10.1002/masy.200650909

21. Jung, J. H.; John, G.; Masuda, M.; Yoshida, K.; Shinkai, S.; Shimizu, T. Langmuir 2001, 17, 7229-7232. doi:10.1021/la0109516

22. Hanabusa, K.; Maesaka, Y.; Kimura, M.; Shirai, H. Tetrahedron Lett. 1999, 40, 2385-2388. doi:10.1016/S0040-4039(99)00195-1

23. Mukkamala, R.; Weiss, R. G. Langmuir 1996, 12, 1474-1482. doi:10.1021/la950666k

24. Watanabe, Y.; Miyasou, T.; Hayashi, M. Org. Lett. 2004, 6, 1547-1550. doi:10.1021/ol049737+

25. Hafkamp, R. J. H.; Feiters, M. C.; Nolte, R. J. M. J. Org. Chem. 1999, 64, 412-426. doi:10.1021/jo981158t

26. Sagawa, T.; Chowdhury, S.; Takafuji, M.; Ihara, H. Macromol. Symp. 2006, 237, 28-38. doi:10.1002/masy.200650504 
27. Sumiyoshi, T.; Nishimura, K.; Nakano, M.; Handa, T.; Miwa, Y.; Tomioka, K. J. Am. Chem. Soc. 2003, 125, 12137-12142. doi:10.1021/ja035085t

28. Becerril, J.; Burguete, M. I.; Escuder, B.; Galindo, F.; Gavara, R.; Miravet, J. F.; Luis, S. V.; Peris, G. Chem.-Eur. J. 2004, 10, 3879-3890. doi:10.1002/chem.200400031

29. Doi, M.; Asano, A.; Yoshida, H.; Inouguchi, M.; Iwanaga, K.; Sasaki, M.; Katsuya, Y.; Taniguchi, T.; Yamamoto, D. J. Pept. Res. 2005, 66, 181-189. doi:10.1111/j.1399-3011.2005.00286.x

30. Caplar, V.; Zinic, M.; Pozzo, J. L.; Fages, F.; Mieden-Gundert, G.; Vogtle, F. Eur. J. Org. Chem. 2004, 19, 4048-4059. doi:10.1002/ejoc.200400105

31. Makarevic, J.; Jokic, M.; Raza, Z.; Stefanic, Z.; Kojic-Prodic, B.; Zinic, M. Chem.-Eur. J. 2003, 9, 5567-5580. doi:10.1002/chem.200304573

32. Friggeri, A.; van der pol, C.; van Bommel, K. J. C.; Heeres, A.; Stuart, M. C. A.; Feringa, B. L.; van Esch, J. Chem.-Eur. J. 2005, 11, 5353-5361. doi:10.1002/chem.200500007

33. Ihara, H.; Sakurai, T.; Yamada, T.; Hashimoto, T.; Takafuji, M.; Sagawa, T.; Hachisako, H. Langmuir 2002, 18, 7120-7123. doi:10.1021/la025535f

34. Becerril, J.; Escuder, B.; Miravet, J. F.; Gavara, R.; Luis, S. V. Eur. J. Org. Chem. 2005, 3, 481-485. doi:10.1002/ejoc.200400629

35. Griffiths, P. C.; Cote, M.; James, R.; Rogueda, P. G.; Morgan, I. R.; Knight, D. W. Chem. Commun. 2005, 3998-4000. doi:10.1039/b505938k

36. Fu, X. J.; Yang, Y.; Wang, N. X.; Wang, H.; Yang, Y. J. J. Mol. Recognit. 2007, 20, 238-244. doi:10.1002/jmr.831

37. Das, D.; Dasgupta, A.; Roy, S.; Mitra, R. N.; Debnath, S.; Das, P. K. Chem.-Eur. J. 2006, 12, 5068-5074. doi:10.1002/chem.200501638

38. Smith, J. M.; Katsoulis, D. E. J. Mater. Chem. 1995, 5, 1899-1903. doi:10.1039/jm9950501899

39. Pantos, G. D.; Pengo, P.; Sanders, J. K. M. Angew. Chem., Int. Ed. 2007, 46, 194-197. doi:10.1002/anie.200603348

40. Zhan, C. L.; Gao, P.; Liu, M. H. Chem. Commun. 2005, 462-464. doi:10.1039/b413259a

41. George, M.; Funkhouser, G. P.; Terech, P.; Weiss, R. G. Langmuir 2006, 22, 7885-7893. doi:10.1021/la0610405

42. Okabe, S.; Ando, K.; Hanabusa, K.; Shibayama, M. J. Polym. Sci., Part B: Polym. Phys. 2004, 42, 1841-1848. doi:10.1002/polb.20067

43. Okabe, S.; Hanabusa, K.; Shibayama, M. J. Polym. Sci., Part B: Polym. Phys. 2005, 43, 3567-3574. doi:10.1002/polb.20620

44. Terech, P.; Bouaslaurent, H.; Desvergne, J. P. J. Colloid Interface Sci. 1995, 174, 258-263. doi:10.1006/jcis.1995.1389

45. Terech, P.; Clavier, G.; Bouas-Laurent, H.; Desvergne, J. P.; Deme, B.; Pozzo, J. L. J. Colloid Interface Sci. 2006, 302, 633-642. doi:10.1016/j.jcis.2006.06.056

46. Dastidar, P.; Okabe, S.; Nakano, K.; lida, K.; Miyata, M.; Tohnai, N.; Shibayama, M. Chem. Mater. 2005, 17, 741-748. doi:10.1021/cm048210o

47. Terech, P.; Furman, I.; Weiss, R. G. J. Phys. Chem. 1995, 99, 9558-9566. doi:10.1021/j100023a038

48. Terech, P.; Allegraud, J. J.; Garner, C. M. Langmuir 1998, 14, 3991-3998. doi:10.1021/la980160c

49. Willemen, H. M.; Marcelis, A. T. M.; Sudholter, E. J. R.; Bouwman, W. G.; Deme, B.; Terech, P. Langmuir 2004, 20, 2075-2080. doi:10.1021/la035041y
50. Andre, D.; Fourme, R.; Bruneauxpoulle, J.; Bosio, L. J. Mol. Struct. 1982, 81, 253-255. doi:10.1016/0022-2860(82)85338-6

51. Moreno, A.; Alegria, A.; Colmenero, J.; Prager, M.; Grimm, H.; Frick, B. J. Chem. Phys. 2001, 115, 8958-8966. doi:10.1063/1.1413742

52. Knight, D. W.; Morgan, I. R. Tetrahedron Lett. 2009, 50, 6610-6612. doi:10.1016/j.tetlet.2009.09.070

53. Chatterjee, A.; Grubbs, R. Angew. Chem., Int. Ed. 2002, 41, 3171. doi:10.1002/1521-3773(20020902)41:17<3171::AID-ANIE3171>3.0.CO ;2-O

54. Kolb, H. C.; Vannieuwenhze, M. S.; Sharpless, K. B. Chem. Rev. 1994, 94, 2483-2547. doi:10.1021/cr00032a009

55. Mitchell, P. C. H.; Parker, S. F.; Ramirez-Cuesta, A. J.; Tomkinson, J., Eds. Vibrational Spectroscopy with Neutrons; Series on Neutron Techniques and Applications, Vol. 3; World Scientific Press: Singapore, 2005.

\section{License and Terms}

This is an Open Access article under the terms of the Creative Commons Attribution License

(http://creativecommons.org/licenses/by/2.0), which permits unrestricted use, distribution, and reproduction in any medium, provided the original work is properly cited.

The license is subject to the Beilstein Journal of Organic Chemistry terms and conditions:

(http://www.beilstein-journals.org/bjoc)

The definitive version of this article is the electronic one which can be found at: doi:10.3762/bjoc. 6.123 